\author{
Introducción al Sistema Interamericano de Derecho \\ Internacional Privado: El Proceso de la Séptima Conferencia \\ Especializada Interamericana sobre DEREcho Internacional \\ Privado (CIDIP-VII) y la Cooperacion Internacional en matéria \\ de Derecho Internacional Privado ${ }^{I}$
}

\title{
John Wilson
}

\section{PROCESO DE CIDIP}

La Organización de los Estados Americanos, dentro de sus diversas labores juridicas, diplomáticas y políticas, tiene el encargo menester menester de desartollar del derecho intemacional privado en el hemisferio occidental. El proceso por medio del cual la OEA juega esta papel importante en la codificación y armonización del derecho internacional privado en la región es el de Conferencias Especializadas Interamericanas sobre Derecho Internacional Privado - mejores conocidas por sus siglas CIDIP. La OEA convoca Conferencias CIDIP aproximadamente cada cuatro a seis años con la principal función de elaboración de instrumentos intemacionales de importancia para los Estados.

La influencia del proceso de CIDIP en las Américas se proyecta por la cantidad y calidad de instrumentos que ha producido y que subsecuentemente han sido adoptados por los Estados Miembros de la OEA. Hasta la fecha, la CIDIP ha adoptado 26 instrumentos, 21 de los cuales se encuentran actualmente en vigor: Asimismo, varias convenciones de la CIDIP han recibido un gran número de ratificaciones estableciendo así un estándar elevado para la codificación del derecho internacional privado.

Mientras la región marcha hacia una etapa de mayor integración económica, la importancia del proceso de CIDIP se acentúa por el crecimiento en el movimiento transfronterizo de personas, bienes y servicios. Esta interdependencia requiere de mayor armonización y estandarización del derecho internacional privado. Como tesultado directo de estas condiciones, el alcance de las Conferencias CIDIP más recientes va más allá de los temas procesales predominartes en anteriores Conferencias (e.g., jurisdicción, conflictos de

\footnotetext{
Oficina de Derecho lnternacional Departamento de Asuntos Jurídicos Mnternacionales

Conferência realizada na Pontificia Universidacie Catolica de Rio de Janeiro

Rio de Jareiro, Brasil, ens 23 de agosto de 2006, gentrimente cedida por Nádia de Araújo e o autor.
} 
leyes, ejecución de sentencias, etc.), abarcando así la reforma de áreas de derecho sustantivo (e.g, derecho comercial, derecho bancario, derecho de transporte, etc.). Asimismo, la CIDIP ha comenzado a utilizar métodos para redactar instrumentos legales diferentes a las convenciones tradicionales, también predominantes en Confetencias anteriores.

\section{INSTRUMENTOS ADOPTADOS}

A la fecha se han realizado seis Conferencias de CIDIP en varias ciudades de las Américas y se han adoptado 26 Instrumentos Interamericanos. Así mismo, actaulmente se estan llevando acabo los trabajos preparativos para séptima Conferencia CIDIP que contempla hasta seis Instrumentos Interamericanos adicionales.

La CIDIP-I, celebrada en la Ciudad de Panamá, Panamá en 1975, adoptó seis convenciones en los temas de comercio internacional y derecho procesal: 1) Conflictos de leyes en materia de letras de cambio, pagarés y facturas; 2) Conflictos de leyes en materia de cheques; 3) Arbitraje comercial intemacional; 4) Exhortos o cartas rogatorias; 5) Recepción de pruebas;y 6) Poderes usados en el extranjero. ${ }^{2}$

La CIDIP-II, celebrada en Montevideo, Uruguay en 1979, adoptó ocho instrumentos intemacionales en los siguientes temas de derecho mercantil intemacional y derecho procesal intemacional, así como en temas relacionados con aspectos generales del derecho intemacional privado: 1) Conflictos de leyes en materia de cheques; 2) Conflictos de leyes en materia de sociedades mercantiles; 3) Eficacia extraterritonial de las sentencias y laudos arbitrales extranjeros; [9] 4) Ejecución de medidas preventivas; [10] 5) Pruebas e información acerca del derecho extranjero; 6) Domicilio de las personas fisicas en el derecho internacional privado; 7 ) Normas generales de derecho internacional privado; y 8 ) Exhortos y cartas rogatorias. ${ }^{3}$

La CIDIP-III, celebrada en La Paz, Bolivia en 1984, adoptó cuatro instrumentos internacionales en los siguientes temas de derecho civil internacional y derecho procesal intemacional: 1) Conflictos de leyes en materia de adopción de menores; 2) Personalidad y capacidad de personas jurídicas en el derecho internacional privado; 3) Competencia en la esfera intemacional para la eficacia extratetritorial de las sentencias extranjeras; y 4) Recepción de pruebas en el extranjero. ${ }^{4}$

i Conferência realizada na Pontificia Universidade Catolica de Rio de Janeiro. Rio de Janeiro, Brasil, em 23 de agosto fie 2006 , gentilunente cedida por Nádia de Araújo e o autot:

2 El texto completo de as seis Convenciones adoptadas por la CIDIP" , así como resimenes de las mismas, pueden serconsultarios en el Intemet en la página web de la Oúcina de Derecho Intemacional, en la siguente dirección: <wwwons.org/dil/esp/ CIDTPI homehtm>.

3 Ej texto completo de las los ocho instumentos Interamericanos adoptados por la CIDIP. II asi como resúmenes de los mismos, pueden ser consultados en el Intemet en la página web de la Oficina de Derecho İntemacional, en la siguiente ditección: $<$ wwwoas.org/dil/esp/CIDIPI_homehtm>.

4 El texto completo de los cuatro instrumentos Interamericanos adoptados por la CIDIP.IJI así como resiunenes de los mismos, pueden ser consultados en el huternet en la página web de la Ofina de Detecho Internacional, en la siguiente dirección: < wwwoas.org/dil/esp/CIDIPII_home.htm> 
La CIDIP-IV, celebrada en Montevideo, Uruguay en 1989, adoptó tres instrumentos intemacionales sobre los siguientes temas de derecho internacional privado: 1) Restitución internacional de menores; 2) Obligaciones alimentarias; y 3) Contratación de transporte intemacional de mercaderías por carretera. ${ }^{5}$

La CIDIP-V, celebrada en la Ciudad de México, México en 1994, adoptó dos instrumentos internacionales sobre los siguientes temas de de recho internacional privado y comercial: 1) Derecho aplicable a contratos intenacionales; y 2) Tráfico internacional de menores. ${ }^{5}$

La CIDIP-VI, cclebrada en la sede de la OEA A en Washington, D.C. en 2002, adoptó tres instrumentos intemacionales sobre los siguientes temas de derecho intemacional privado: 1) Armonización de legislación sobre garantías mobiliarias; 2) Carta de porte directa uniforme negociable para el transporte intemacional por carretera; y 3 ) Carta de porte directa uniforme no-negocialle para el transporte intemacional por carretera. ${ }^{7}$

Finalmente, la CIDIP-VII, un proceso actualmente en marcha, se encuentra negociando seis instrumentos intemacionales sobre dos temas específicos. En materia de Protección al Consumidor la CIDIP-VII, elaborará una Convención sobre Ley Aplicable, una Ley Modelo sobre Jurisdicción, y una Ley Modelo sobre Restitución Monetaria. En materia de Registros Electrónicos la CIDIP-VII elaboratá una serie de Formularios Registrales Uniformes (incluyendo formularios de inscripción, extensión, modificación, cancelación y ejccución), una Guía sobre Registros Mobiliarios, y una Guía sobre Registros Electrónicos. para mayor información sobre los trabajos preparativos actuales sobre estos instrumentos y foro de discusión virtual de la CIDIP-VII, véase la siguiente página web: http:/ / wwwwoas.org/ dil/esp/CIDIPVII_home.htm.

\section{CIDIP-VII}

La Asamblea General de la Organización de los Estados Americanos, por medio de su resolución AG/RES. 1923 (XXXIII-O/03) y AG/RES. 2033 (XXXIV-O/04), convocó la Séptima Conferencia Especializada Interamericana sobre Derecho Internacional Privado y solicito al Conseio Permanente que realizara consultas con las Estados Miembros sobre posibles temas para la agenda.

5. El texto completo de las tres Convenciones Interamencar1as adoptadns por la CIDIP-IV así cono resúrnenes de las mismas, pueden ser consultados en el Intenet en la página web de la Oficina de Derecho Internacional, en la signiente dirección: <ururvoas org/dil/esp/CDIPY _homelatm>.

"Bl texto completo de las dos Convenciones Jnteramencanas adoptadas por la CHDTP-V así como resumeaes de las mismas, pueder set consultados en el Intentet en la página web de la Oficina de Derecho lnternacional, en la skguiente dirección: <wwwoas.org/dil/esp/CIDIPV_Llomehtm>

7 El texto completo de los tres instrumentos Interameticanos adoptados por la CIDIP-Vi, puede ser consultado en el Intemet en la página web de la Oficina de Derecho Intemacional, en la sigujented dirección: <wwwoas.org/dil/esp/CIDIPV_home htm>. 
Para cumplir con este mandato, el Consejo Permanente, por medio de su Comisión de Asuntos Jurídicos y Políticos, solicitó que los Estados Miembros presentaran propuestas para la Agenda. Las delegaciones de Brasil, Canadá, El Salvador, Estados Unidos, México, Pení, y Uruguay presentaron los siguientes temas para inclusión en la Agenda Comercio Electrónico, Protección al Consumidor, Flujos Migratorios de Personas, Responsabilidad Civil Extracontractual, Transporte, Insolvencia Transfronteriza, Jurisdicción Internacional, Protección de Menores, y Grados Universitarios y Profesiones.

Para llegar a los temas elegidos para la CIDIP-VII, el proceso también tomo en consideración los temas cubiertos por las CIDIP anteriores, así como la lista de temas propuesta en la sesión plenaria funal de la CIDIP-VI. Estálista, contenida en la tesolución CIDIP-VI/RES.1/02, incluye los siguientes temas. 1) Desarrollo de un sistema de registro computarizado interamericano; 2) Continuación del trabajo sobre transporte que abarquen enfoques multimodales, incluidos el transporte por carretera, ferroviario, por agua y por aire; 3) Valores de inversión; 4) Insolvencia comercial transfronteriza; 5) Comercio electrónico; 6) Derechos legales intemacionales para la transferibilidad de bienes tangibles e intangibles en el comercio intemacional; 7 ) Movinientos transfronterizos y flujos migratorios de personas; y 8) Protección internacional a personas adultas cuyas facultades personales son insuficientes."

Finalmente, los Estados Miembros también tomaron en consideración los escritos y opiniones del Comolté Jutidico Interamericano (incluyendo su documento titulado CIDIPVII y Etapas Sucesiara CII/doc.74/01), que presentó los resultados de una encuestad a expertos de derecho internacional privado con relación al futuro de la CIDIP, incluyendo temas para la agenda. Entre otros temas mencionados, esta recomendación incluyo los siguientes temas: 1) Comercio Electrónico; 2) Migración y flujo de personas; 3) Arbitraje y resolución de controversias; 4) Protección al consumidor; y 5) Protección de menotes. ${ }^{10}$

Aunque los Estados Miembros formalmente presentaron un total de ocho temas (incluyendo variaciones de los instrumentos y sub-temas posibles bajo cada uno), y estudiarion la posiblidad de un número significativo de temas adicionales, acordaron que la CIDIP-VII se limitaría a un máximo de dos. Por consecuencia, la Comisión de reunió con los Estados Micmbros en sesiones formales e informales para reducir el numero de temas propuestos, estableciendo así una agenda final consistente en Protección al Consumidor y Registros Electrónicos.

8 La frascripción original de la sesión plenaria final de la CIDIP̉. VI puede ser consulada en el hatenet en la página web del

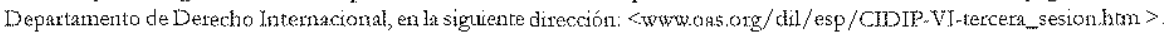

" Vl texto completo de la resolución CIDIP.VI/RES. 1/02 puede ser consultado en el tratemet en la página web del Departanento de Derecho Intermacional, en la siguente direccion: <wwwons,otg/dil/esp/CIDIPVI-Res1-02_esphtm>

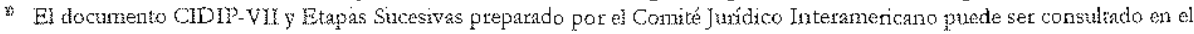
Intexnet en la página wejo del Departamento de Dexecho Intemacional, en la siguiente dirección: <xwwoas.org/dil /esp/ derecho_internacional_privado_conferencias_introducion.him $>$. La lista de temas propuestos para la CIDIP-VII puede ser consultada en el lnternet en la página web del Departanento de Derecho Intenacional, ena la siguiente dirección: <wwwoas.org/dilesp/terecho_intetancional_privado_conferencias_posiblesterascidipvithiri> 
Basándose en estas recomendaciones, la Asamblea General, por medio de su resolución AG/RES 2065 (XXX-O/05), formalmente aprobó la siguiente agenda: (tcma uno) Protección al Consumidor - Ley Aplicable, Jurisdicción, y Restitución Monetaria (Convenciones y Leyes Modelo); y (tema dos) Garantías Mobiliarias: Registros Ellectrónicos para Implementación de la Ley Modelo Interamericara sobre Garantías Mobiliarias. Habiendo establecido el temario de la Conferencia, la Resolución AG/RES 2065 solicitó al Consejo Pemanente que establezca la metodología para los trabajos preparativos necesarios para elaborar los ins trumentos interamericanos a ser considerados por la CIDIP-VII.

\section{TEMAS PARA LA CIDIP-VII}

La Asamblea General, como se mencionó, aprobó la elaboración de instrumentos sobre protección al consumidor y sobre registros electrónicos, de la manera descrita a continuación.

\section{A. Protección al Consumidor:}

La Comisión de Asuntos Jurídicos y Políicos, como el primer paso en la elaboración de tratados o leyes modelos sobre los temas seleccionados, solicitó que los Estados Miembros presentaran borradores de instrumentos y comentarios para cada uno de los temas y subtemas aprobados por la Resolución 2065. Sobre el primer tema, la delegación de Brasil presento una propuesta de Convención Interamericana sobre la Ley Aplicable a Algunos Contratos y Relaciones de Consumo; la delegación de los Estados Unidos presento un esquema para una Ley Modelo sobre Mecanismos de Restitución Monetaria para Consumidores; y, la delegación de Canadá presentó un informe sobre la Jurisdicción y la Protección al Consumidor en el Comercio Electrónico.

Las delegaciones acordaron que los trabajos de la CIDIP.VII sobre protección al consumidor producirían tanto una Convención sobre ley aplicable como una Ley Modelo sobre restitución monetaria: la Convención crearía un sistema para determinar las reglas aplicables a consumidores litigantes, mientras que la ley modelo complementaría dicho instrumento con mecanismos para la restitución cuando el litigio no prevé las soluciones más efectivas. En conjunción, estos dos instrumentos que conformaria el trabajo sobre el tema uno de la CIDIP-VII y cubririan los aspectos más sobresalientes de la protección al consumidot en las Américas.

1) Convención sobre Ley Aplicable: La propuesta presentada por Brasil (CP/CAJP2094/03 add. 3-a) (Adjunto como ANEXO I) establece las bases para redactar una convención sobre ley aplicable en transacciones del consumidor. A este efecto, el documento proporciona reglas específicas sobre la definición de consumidor, establece que contratos al consumidor (especialmente esos concluidos por algún medio de comunicación electrónica) serán regulados por la ley del país de residencia del consumidor o por la ley más favorable a este. El proyecto contiene excepciones a su aplicación para algunos casos excluidos o cuando los temas en disputa se cubren por otros tratados internaciones. La Convención también proporciona 
reglas específicas sobre algunos contratos especialmente ptoblemáticos, incluyendo contratos de viaje y turismo así como contratos de tiempo compartido.

ii) Ley Modelo sobre Mecanismos de Restitución al Consumidor: El esquema presentado por los Estados Lnidos propone lá elaboración de una Ley Modelo sobre mecanismos de restitución monetaria pata proteger a consumidores dañados económicanente (Adjunto como ANEXO II). Un instrumento de este tipo sería particularmente importante para daños de un valor monetario que no amerite el empleo de un procedimiento legal formal bajo la Convención propuesta. La propuesta de los Estados Unidos proporciona varias posibilidades para obtener restitución económica para los consumidores dañados, incluyendo el uso de mecanismos judiciales como los tribunales de daños menores, adjudicación administrativa para daños menores, y acciones judiciales colectivas por parte del gobiemo (pomens partiae) o por parte de asociaciones. Una ley modelo de este tipo proporcionaxia los elementos para remediar quejas de los consumidores individuales, para que estos puedan entablar acciones judiciales colectivas cuando varios consumidores son dañados dentro de una jurisdicción, y establecería los principios para un sistema de remedios para daños económicos de menor cuantía.

iii) Ley Modelo o Convención sobre la Protección al Consumidor en el Comercio Electrónico: El documento presentado por Canadá (CP/CAJP-2094/03 add. 5-a, Adjutno como ANNEXO III) proporciona las bases para un proyec to de convención o ley modelo sobre jurisdicción para transacciones al consumidor sobre el Internet. Este instrumento también podría operar en coordinación con los instrumentos propuestos por las delegaciones de Brasil y Estados Unidos con respecto a temas especiales de jurisdicción en transacciones clectrónicas no cubiertos por estos otros dos documentos. El propósito principal de la propuesta de Canadá sería proveer opciones legislativas para la jurisdicción relacionada al uso del Intemet por parte de consumidores. La propuesta inicial incluye reglas tanto para establecer la juris dicción del un Estado para resolver controversias de este tipo (jurisdicción aplicable) como la ley del estado aplicable a las mismas (ley aplicable).

\section{B. Registros Electrónicos:}

El segundo tema aprobado por la Asamblea General es Registros Electrónicos para Implementación de la l. ey Modelo Interamericana sobre Garantias Mobiliarias -un instrumento aprobado en la CIDIP-VI. A la fecha, ningún Estado Miembro ha presentado propuestas especificas sobre este tema. Las discusiones preliminares entre los estados, sin embargo, se han enfocado sobre la elaboración de instrumentos internacionales que regulen tres aspectos principales de lo que debería ser el componente registrai de la Ley Modelo Interamericana sobre Garantías Mobiliarias: (1) la elabotación de un fomnulario registral uniforme interamericano; (ii) la elaboración de lineamientos registrales para la aceptación, conservación, y diseminación de información electrónica; y (iii) la elaboración de lineamientos pata la interconexión de registros de diferentes jurisdicciones para casos en los cuales bienes mucbles tienen contacto con más de una juris dicción o casos en donde es tos se trasladan de una jurisdicción a otra. 
i) Formulario Registral Uniforme: La Ley Modelo de garantias mobiliarias establece que el perfeccionaniento de una garantia sobre bienes muebles por medio de la inscripción de un formulario registral de una págináa. Auque la Ley Modelo proporciona reglas básicas que los estados pueden seguir en la elaboración de sus propios formatos de registro, la CIDIP-VII debería considerar la elaboración de un formulatio uniforme para uso por todos los Estados Miembros. Un sistema de ese tipo hamonizaría los registros de los estados, permitiría fácil acceso a información pública respecto el estado de propiedad, crearía mayor certeza en la inscripción de garantías mobiliarias, y facilitatía la inscripción por partes en situaciones transfronterizas.

El propósito principal de un formulario unifotne sería buscar el balance adecuado entre tres objetivos principales de una inscripción: la obligación del tegistrante de perfeccionar su garantía; los derechos del ceudor de asegurar una inscripción precisa y autorizada; y la necesidad del acceso a la información del tegistro por parte de terceros interesados para hacer su determinación sobre bienes sujetos a un gravamen. Por tal razón, un proyecto de formulario registral uniforme deberá seguir los reglas propuestas por la L.ey Modelo y proporcionar la información necesaria para dar aviso a terceros de que los bienes de un deudor pueden estar en gravados por un préstamo. Basándose en los lineamientos de la Ley Modelo, un formulario registral debe requerir el nombre del deudor, nombre del acreedor, y una descripción de los bienes en garantía - suficiente información para dar aviso a terceros sin sobrecargar a la parte registrante y sin violar los derechos del deudor a una inscripción certera y autorizada.

Aunque el fomulatio registral puede tomar lugar como un documento en papel, los trabajos de la CIDIP-VII se deben enfocar en la creación de un formulario electrónico que puede ser creado, registrado, conservado, y consultado en un medio totalmente electrónico. Dicho documento deberá ser simple y consistir mexamente de información revelada en un medio electrónico.

ii) Lineamientos para un Registro Electrónico: La elaboración de un instrumento internacional sobre registros electrónicos necesariamente parte de la premisa que la tecnología puede jugar un papel importante en hacer el proceso de registro mas eficiente, mejorando la forma en que las inscripciones se realizan, se conservan, y se consultan, y debe considerar que la inscripción electrónica es más rápida y e ficiente que métodos manuales tradicionales y que puede realizarse desde locales remotos, incluyendo jurisdicciones internacionales. Por tal razón, los trabajos de la CIDIP-VII se deben enfocar en la elaboración de lineamientos que automaticen estos procesos del registro.

La CIDIP-VII debe cubrir varios temas de importancia en el cambio de registros basados en papel a un registro principalmente electrónico, tomando en consideración la necesidad de crear un proceso de registro uniforme que facilite la inscripción desde ubicaciones remotas, y que elabore reglas distintas para el proceso de calificación de inscripciones manuales a diferencia de las inscripciones electrónicas. Así mismo, debe elaborar nuevas soluciones para determinar la jurisdicción registral en la cual se debe realizar la inscripción, favoreciendo, de ser posible, un sistema electrónico centralizado. 
Finalmente, los lineamientos para crear registros electrónicos para uso con la Ley Modelo deben enfocarse sobre la creación de mayor flexibilidad en requisitos notariales y de ratificación, así como permitir el uso de firmas electrónicas en la inscripción. El objetivo final de dichas reglas deberá ser mayor eficacia y celeridad, menores costos, y mayor precisión, uniformidad, y coordinación entre los registros de los Estados Miembros.

iii) Interconectividad de Registros: La Ley Modelo reconoce que el tipo de bienes muebles de mayor valor económico frecuentemente consiste en bienes intangibles/ incorpóreos sin contacto fisico a una jurisdicción específica. Así mismo, reconoce que bienes muebles de alto valor frecuentemente se trasladan de una jurisdicción a otra. Por lo tanto, un tercer instrumento o componente de los trabajos preparativos sobre esta materia, debe consistir en un proyecto de guía y lineamientos para la conectividad de registros de diferentes jurisdicciones. Dicha conectividad pemitiría la elaboración de reglas sobre el lugar de inscripción de una garantía que cubre bienes intangibles con contactos en más de una juxisdicción, así como reglas de registro para casos en donde bienes se trasladan de una jurisdicción a otra Por otro lado, los trabajos preparativos sobre la materia deberán crear los métodos necesarios para permitir que registros locales puedan tecibir y transmitir inscripciones de garantías, as como permitir consultas sobre las mismas desde otras jurisdicciones.

\section{Estudios Paralelos:}

Los Estados Miembros acordaron limitar los temas de la CIDIP-VII a los discutidos con anterioridad, pero acordaron también a labores de estudio paralelas sobre temas que, a pesar de su importancia a las delegaciones, no llegan a conformar la agenda final. Estas labores paralelas se enfocan principalmente sobre temas que los Estados Miembros sienten que no se han desarrollado lo suficiente para permitir el consenso en la elaboración de un instrumento internacional pero que, sujetos a un dialogo paralelo entre los estados, puede llevar a proyectos para futuras Conferencias de CIDIP.

i) Jurisdicción Internacional: La Delegación de Uruguay presentó un documento titulado "Bases de una Convención Interamericana sobre Jurisdicción Internacional" (CP/ CAJP.2094/03 add.6-b). La Resolución AG/RES. 2065 establece que este documento puede ser considerado para estudio futuro, y puede tomar parte como un estudio paralelo durante la CIDIP-VII. El propósito principal de esta Convención sería establecer la jurisdicción internacional directa de los estados parte de la misma.

ii) Registros de Títulos: La Delegación de Estados Unidos también solicitó el posible estudio paralelo de registros de títulos, incluyendo títulos de bienes inmuebles y otros tipos de propiedad. Este estudio tomaría ventaja del conocimiento y dialogo para la elaboración de instrumentos internacionales bajo el tema dos de la agenda y exploraría la posibilidad de extender los conceptos de registro electrónico más allá de bienes muebles. 


\section{METODOLOGÍA DE TRABAJO PARA LA CIDIP-VII}

La Resolución de la Asamblea General AG/RES. 2065 (XXXV-O/05) encomendó al Consejo Pemanente que estableciera la metodología para la preparación de los instrumentos interamericanos a ser considerados por la CIDIP-VII. Los pasos principales en dicho proceso incluyen la designación de expertos autorizados, la organización de reuniones y comunicaciones de dichos expertos, y la creación de un calendario para los trabajos preparativos.

\section{A. Designación de Expertos:}

El primer paso en la elaboración de los instrumentos para la CIDIP.VII es la designación de expertos gubernamentales y no gubemamentales para cada tema y sub-tema.

Los Estados Miembros deberán proponer expertos vía designación o ficial por sus respectivas Misiones. Expertos designados deberán ser proveídos de autotidad para participar y negociar los textos de acorde con las instrucciones políticas y sustantivas de sus respectivos gobiernos.

Cada estado miembro deberá designar por lo menos un Experto Gubenamental para cada tema de la CIDIP-VII. Estos expertos deberán contar con la experiencia y conocimiento sobre el tema que se les encomienda así como con autorización gibemamental para negociar e implementar una convención u otro instrumento sobre el tema. Así mișmo, aunque a los Estados Miembros se les recomienda que designen a expertos sobre derecho intemacional privado, también se les recomienda que designen a funcionarios de las dependencias gubernamentales con autoridad específica sobre los temas de la agenda - es decir, los Estados Miembros deberían designar a funcionarios de la agencia gubernamental para la protección del consumidor para participar como expertos en el tema uno y a funcionatios del registro comercial como expertos en el tema dos.

Una vez que los Estados Miembros designen a sus expertos, sus Misiones deberán informar dichos nombramientos al Departamento de Asuntos Juridicos Internacionales por medio de nota oficia. Dicha comunicación deberá mencionar si la designación del experto es para el grupo de trabajo bajo el tema uno o bajo al tema dos de la agenda, y deberá contener el nombre, posición y una reseña biográfica de cada experto designado.

Además de expertos gubemamentalcs, la Asamblea General solicito Solicitar al Comité Jurídico Interamericano que presente sus comentarios y observaciones con relación a los temas de la agenda para la CIDIP VII y solicito a la Secretaría General a que explore formas de colaboración con organizaciones internacionales, incluyendo la Conferencia de la Haya sobre Derecho Intemacional Privado, la Comisión de las Naciones Unidas sobre el Derecho Mercantil Intemacional (UNCITRAL), el lnstituto Internacional para la Unificación del Derecho Privado (UNIDROIT), el Banco Interamericano de Desarrollo, entre otras, involucradas en el proceso de redacción y promoción de instrumentos internacionales compatibles con esos elaborados en el proceso de la CIDIP. La Secretaria General trabajará con diciıas instituciones para asegurar su participación en el proceso y nombrará a expertos no gubernamentales a los grupos de 
trabajo, incluyendo a instituciones de la sociedad civil y asociaciones profesionales sobre los temas de la agenda. Los Estados Miembros también deben alentar la participación dentro de los trabajos preparativos para CIDIP-VII a académicos locales y otros expertos no gubernamentales, así como miembros de la sociedad civil y asociaciones profesionales.

Una vez designados, se les requerirá a los expertos que se inscriban por Intemet para el Grupo de Trabajo sobre el tema al cual se le haya nombrado. Dicha inscripción se llevara acabo en la página de Internet del Departamento de Asuntos Jurídicos Internacionales de la Secretaria General: www.oas.org/dil.

\section{B. Comunicaciones y Reuniones de Expertos:}

El segundo paso en el proceso de CIDIP requiere el establecimiento del método por medio del cual los expertos gubernamentales y no-gubernamentales negociaran y elaborarán los instrumentos sobre protección al consumidor y registros electrónicos.

Las reuniones de expertos han sido el medio principal para el dialogo y negociación en previas conferencias CIDIP y, por lo tanto, deben ser realizadas conforme los fondos disponibles. A este efecto, la Secretaría General, con el apoyo de los Estados Miembros, debe realizar esfuerzos para buscar los fondos necesarios para estas reuniones y trabajar con los Estados Miembros dispuestos a ser anfitrión de alguna reunión de expertos.

Alternativamente, los Estados Miembros deben alentar el uso del Intemet para el dialogo y negociación entre expertos y otros participantes. A este efecto, el Departamento de Asuntos Jurídicos Internacionales ha diseñado una página de Internet para auspiciar el dialogo en-línea entre expertos en todas las fases del proceso de negociación. Este sistema proporcionara acceso directo a la documentación de la CIDIP-VII así como informes sobre los avances en la redacción de los mismos. El sistema también será el método preferido para la comunicación entre las delegaciones y la Secretaria General.

Este foro de Internet para el Grupo de Expertos proporcionara instrucciones pasopot-paso tanto para el proceso de inscripción de los participantes como para el dialogo entre los mismos. Así mismo, el sistema creara dos foros distintos, uno para expertos sobre protección al consumidor y el otro para expertos sobre registros electrónicos. Los expertos de los estados deberán, en primer lugar, inscribirse al foro correspondiente y recibirán un nombre de usuario y contraseña. Una vez que el experto acceda al sistema, tendrá acceso a todos los documentos y borradores utilizados durante el proceso de negociación. Dichos expertos también utilizarán el sistema para comunicar los comentarios y posición oficial de sus delegaciones con respecto a los documentos y para solicitar información de la Secretaría General por medio de su Departamento de Asuntos Jurídicos Internacionales. Dicho Departamento se encargara de monitorear los foros, revisar y actualizar los borradores documentos basándose en las observaciones de los expertos, y establecerá un calendario de actividades para el desarrollo de los trabajos preparativos y la participación de los expertos.

Aunque un Grupo de Expertos basado en el Internet no se ha utilizado para Conferencias CIDIP anteriores, este sistema proporcionará una manera más eficaz para la 
participación de todos los Estados Miembros. Sin embargo, debido a la novedad del sistema, los Estados Miembros tendrán la oportunidad de presentar también sus comentarios y observaciones sobre el la estructura, desarrollo y capacidades técnicas del mismo, el cual intentará acomodar las preocupaciones y capacidades de todos los expertos participantes. Los Estados Miembros deberán notar, sin embargo, que debido a limitaciones de recursos, los elementos del sistema aparecerán solamente en ingles y español, que serán los lenguajes del grupo de trabajo. Por otro lado, las participaciones de los expertos aparecerán solamente en el lenguaje original. Por lo tanto, los Estados Miembros deberían, en la manera posible, designar expertos que puedan leer las contribuciones de otros miembros en ingles y español.

Por último, algunos Estados Miembros han propues to la realización de reuniones del Grupo de Expertos por medio de videoconferencia. De acordarse por parte de los Estados, videoconferencias y otros métodos de comunicación electrónica podrían complementar las reuniones y comunicaciones de expertos en el Internet y en persona.

\section{LOS INSTRUMENTOS DE CIDIP EN MATERIA DE COOPERACIÓN}

\section{A. Introducción:}

La aplicación y desarrollo del derecho intemacional depende en gran medida de la cooperación jurídica y judicial entre Estados. Ella representa un medio importante de coordinación entre los funcionarios públicos de diferentes páses y es fundamental para lograr los fines contenidos en un marco jurídico específico. El sistema interamericano, conformado por un marco legal de convenciones y programas sobre cooperación jurídica y judicial y asistencia legal mutua, contiene los componentes necesarios pata configurar un régimen intemacional efectivo en materia de derecho internacional público y de derecho intemacional privado.

Para asegurar el desarrollo en esta área, la REMIA II encomendó a los Estados miembros que realizaran una "evaluación de las convenciones interamericanas en vigor en materia de cooperación jurídica y judicial a fin de identific ar las medidas para su efectiva

aplicación o, en su caso, determinar la necesidad de adecuar el marco jurídico existente en el hemisferio."

Un primer paso en el cumplimiento del mandato de la REMJA consistió en el desarrollo de actividades de cooperación en materia penal y extradición. La presente propuesta recomienda, como un segundo paso, dar comienzo a estas mismas labores pero en materia de derecho civil, incluyendo el detecho procesal, el derecho de familia y el detecho comercial.

Con el objetivo de dar un cumplimiento comprehensivo al mandato de la REMJA en materia de cooperación, el presente documento propone que se emplee una metodología para el desarrollo de la cooperación en materia de derecho civil similar a la ya seguida a la cooperación en materia de derecho penal. 


\section{B. Red de Autoridades Centrales:}

La REMJA I concluyó que la cooperación jurídica internacional es esencial para el desartollo de los sistemas de justicia en los Estados miembros de la OEA y encomendó a estos "proseguir con el perfeccionamiento de los instrumentos jurídicos interamericanos de cooperación en materia legal, para lo cual es necesario que cada Estado evalúc la aplicación efectiva de los actuales instrumentos, aplique medidas para su mayor difusión, y promueva la formulación de otros instrumentos que fueren necesarios para hacer frente a las nuevas necesidades." Asimismo, esta REMJA solicitó a la Secretaría General de la OEA un "estudio sobre los obstáculos para la aplicación efectiva de los tratados de cooperación jurídica y judicial."

Por lo tanto, una de las iniciativas más importantes adoptadas por la REMJA ha sido la creación de una red de autoridades centrales señaladas en las convenciones interamericanas en materia de asistencia legal mutua. A la fecha, los logros en la designación de autoridades centrales, la facilitación y seguridad de las comunicaciones entre éstas, la cooperación entre los Gobiemos, y la capacitación de funcionarios competentes, representan un avance significativo en el trabajo de la Otganización y de sus Estados miembros, con el permanente apoyo de la Secretańa General, y aportan modelos a seguir en otras áreas de cooperación jurídica y judicial.

Estas actividades brindan la oportunidad de crear un foro en el cual las autoridades centrales de todos los Estados miembros de la OEA se puedan reunir para discutir temas vitales para la cooperación juridica y judicial en el sistema interamericano. A la fecha, la mayoría de los Estados miembros de la OEA han designado su autoridad central bajo la Convención Interamericana sobre Asistencia Mutua en Materia Penal, las que en muchos casos podrían también participar como autoridades competentes con relación a otras convenciones en materia de cooperación juńdica.

Esta red de funcionarios de cooperación intemacional puede también ayudar a formular recomendaciones para la implementación de asistencia legal mutua en otras áreas, asumiendo un papel importante en la fomulación de políicas con respecto a otros proyectos de cooperación dentro del marco interamericano. La importancia de estas funciones, junto con las relaciones y contactos personales entre los oficiales designados para las mismas, son fundamentales para la operación y promoción de la cooperación juridica y judicial en el hemisferio.

Bajo los auspicios de la REMJA se han ido desattollando herramientas importantes que han servido para fomentar las actividades de cooperación jurídica y judicial entre los Estados miembros. La página de Internet sobre asistencia legal mutua del Departamento de Astuntos Jurídicos Intemacionales de la Secretaria General de la OEA, por ejemplo, proporciona una herramienta que los usuarios pueden emplear para acceder a la legislación y la información necesaria para realizar trámites con las autoridades centrales de la región. Essta página proporciona también, mediante su sección privada, la posibilidad de un foro para que los funcionarios gubernamentalcs y autoridades centrales intercambien confidencialmente información que pudiese ser de beneficio para la operación del sistema. 
El sistema de correo electrónico seguro desarrollado por el grupo de trabajo y por la Secretaria General a través de su Oficina de Servicios de Información y Tecnología, juega un. papel en el intercambio efectivo y seguro de las comunicaciones formales e informales entre autoridades centrales y en el suministro de un sistema de mayor valor probatorio, importante para la transmisión de requerimientos e información en las cortes de cada país.

En resumen, las actividades realizadas hasta la fecha representan un paso importante en el cumplimiento de las recomendaciones de las REMJAs en materia de cooperación jurídica y judicial y pueden servir como modelo a seguir en otras áreas, dando así un total cumplimiento a dichas recomendaciones.

\section{Cooperación en Materia de Derecho Civil:}

Una primera área en la que se podría ampliar las actividades en materia de coopexación podría incluir la presentación y manejo de exhortos y cartas rogatorias y la presentación de pruebas en los litigios internacionales. Actualmente, la OEA desarrolla una actividad importante con respecto a la cooperación en acciones penales - desde la identificación y enjuiciamiento de criminales, al intercanbio de pruebas y a la extradición de personas pero no con respecto a las acciones civiles paralelas que con frecuencia son necesarias para completar el proceso legal en el átea intemacional. Más aún, algunos requerimientos judiciales pueden caer fuexa del alcance directo de las actividades que desarrolla actualmente la Organización, los que pueden incluir el emplazamiento de personas, la toma de testimonios, la obtención de expedientes y de datos bancarios, así como la obtención de otros tipos de pruebas. Por tal razón, el sistema se vería mejorado a través de una mejor complementación entre las convenciones de derecho intemacional público (penal) y las de derecho intemacional privado (civil) en lo que se refiere a la asistencia legal mutua y al derecho procesal. El inicio de nuevos proyectos sobre estos temas, derivados de mandatos de la REMIA y con el soporte de la Secretaría General de la OEA, sería un complemento natural a las actividades que se desempeñan actualmente.

Ia Convención Interamericana sobre Exhortos o Cartas Rogatorias y la Convención Interamericana sobre la Recepción de Pruebas en el Extranjero han sido ratificadas por numerosos Estados miembros de la OEA. Sin embargo, actualmente no se dispone de un sistema de asistencia legal mutua entre los Estados que esté en funcionamiento. La aplicación de la Convención sobre Exhortos o Cartas Rogatorias y su Protocolo Adicional referidos a la presentación de solicitudes oficiales en el extranjero en material civil se podría fortalecer de sobremanera si se emprendieran las labores que ya se han realizado en materia penal. De la misma manera se fortalecería la aplicación de la Convención sobre Recepción de Pruebas referida a la obtención de información en jurisdicciones extranjeras, que constituye un instrumento vital para la ubicación, la extradición, y el enjuiciamiento de criminales en el ámbito transnacional en acciones penales y civiles simultáneas, así como para la ubicación y repatriación de fondos depositados en instituciones frnancieras en otros paises.

Otra área que se podria beneficiar por este tipo de complementación se vincula al derecho de familia (privado/civi) en lo que tiene que ver con el secuestro, tráfico y restitución 
de menores, así como con el pago de las pensiones alimenticias. Por último, estos mecanismos también serian sin duda de gran utilidad para la cooperación jurídica y judicial en materia comercial.

\section{Cooperación sobre Convenciones en Materia Procesal, Familiar y Comercial:}

Como se mencionó anteriomente, la REMIA II encomendó a los Estados miembros que evalúen la aplicación de las convenciones interamericanas actuales en materia de cooperación jurídica y judicial y asistencia legal mutua para mejorar su cumplimiento y exhortó a los Estados miembros a que, en los casos estipulados, designen autoridades centrales para asegurar la efectiva aplicación de estos tratados.

En materia de derecho intemacional privado existen diez convenciones interamericanas que requieren la designación de autoridades centrales por parte de los Estados parte. Es pues importante que los Estados que no lo han hecho procedan a designar dichas autoridades, instrumento imprescindible para el logro de los objetivos de estos acuerdos. Los textos de dichas convenciones pueden ser consultados por tema o por fecha en la siguiente página de Internet: www.oas.org/dil/esp/derecho_internacional_privado_materias.htm.

i) Convenciones en Materia Procesal ( $A N E X O$ V):

El sistema interamericano se compone de los siguientes cinco instrumentos en materia procesal, los que requieren de la cooperación juridica y judicial para cumplir con sus propósitos:

La Convención Interamericana sobre Exhortos o Cartas Rogatorias establece las normas que regulan el reconocimiento y aplicación de las cartas rogatorias que tengan por objeto la realización de actos procesales incluyendo notificaciones, citaciones, emplazamientos en el extranjero, así como la recepción de pruebas e informes. Con respecto a esta Convención, once de diecisiete Estados que la han ratificado han designado una autoridad central.

El Protocolo Adicional sobre Exhortos o Cartas Rogatorias establece las reglas procesales para facilitar la diligencia de estos trámites y presenta formatos impresos de las cartas rogatorias a ser presentadas a las autoridades centrales. Con respecto a este Protocolo, seis de catorce Estados parte han designado una autoridad central.

La Convención Interamericana sobre Prueba e Información Acerca del Derecho Extranjero establece las normas para la cooperación intemacional entre Estados parte en la obtención de elementos de prueba e información acerca del derecho intemo de cada uno de ellos. Con respecto a esta Convención, ocho de los doce Estados parte han cumplido con su obligación de designar una autoridad central.

La Convención Interamericana sobre Recepción de Pruebas en el Extranjero establece el marco aplicable a los exhortos o cartas rogatorias que soliciten la obtención de pruebas o informes en el extranjero (ya sean estas de índole civil o comercial) emitidas por la autoridad competente de uno de los Estados parte a la autoridad competente de otro. Con respecto a esta Convención, siete de los once Estados parte han designado una autoridad central. 
El Protocolo Adicional a la Convención Interamericana sobre Recepción de Pruebas en el Extranjero es tablece la metodología para facilitar la cooperación intemacional en los procedimientos judiciales de diligencia de exhortos o carta rogatorias bajo la Convención y proporciona anexos que sirven como formulatios impresos de las cartas rogatorias a ser presentados a las autoridades centrales. Con respecto a este Protocolo, sólo uno de cuatro Estados parte en el Protocolo han designado autoridades centrales.

Para mayorinformación sobre estos instrumentos en materia de derecho procesal y la designación de autoridades centrales, véase el ANEXO V del presente documento y la siguiente página wels: www.oas.org/dil/esp/derecho_intemacional_privado_materias_ejecucionyderechoprocesal.htm.

\section{ii) Convenciones en Materia de Familia y Protección de Menores (ANEXO VI);}

El sistema jurídico interamericano se compone de las siguientes tres convenciones en materia de derecho familiar y protección de menores:

La Convención Interamericana sobre Tráfico Internacional de Menores establece un sistema de cooperación jurídica para la protección integral de menores por medio de la instrumentación de mecanismos adecuados que permitan garantizar el respeto de sus derechos y que promueva la educación acerca del tráfico intemacional de menores como una preocupación universal. La Convención es tablece que los Estados parte designarán una o más autoridades centrales encargadas de los aspectos penales y civiles del tráfico intemacional de menores. Con respecto a esta Convención, sólo tres de los once Estados parte han designado una autoridad central.

La Convención Interamericana sobre Restitución Internacional de Menores establece el proceso para asegurar la pronta restitución de menores que hayan sido trasladados o retenidos ilegalmente en cualquier Estado parte y para asegurar los derechos de visita y custodia o guardia de los padres. Con respecto a esta Convención, ocho de trece Estados parte han designado una autoridad central.

La Convención Interamericana sobre Obligaciones Alimentarias establece el derecho aplicable a Ias obligaciones alimentarias respecto de menores y ex-cónyuges, y establece la competencia y regula la cooperación jurídica y judicial intemacional cuando el deudor de alimentos tenga su domicilio en un Estado parte y el acreedor en otro. Con respecto a esta Convención, sólo dos de once Estados parte han desiguado una autoridad central.

Para mayor información sobre estos instrumentos de derecho de familia y protección de menores, así como la designación de autoridades centrales, véase el ANFXO VI del presente y la siguiente página web: www.oas.org/dil/esp/derecho_internacional_privado_materias_familiar.htm.

ii) Convenciones en Materia Comercial y Medidas Cautelates (ANEXO VII):

Con respecto a otras convenciones de derecho civil que requieren de la cooperación juridica y judicial, la Convención Interamericana sobre Arbitraje Comercial Internacional establece que las sentencias o laudos arbitrales finales tendrán la misma fuerza que una sentencia judicial y exige el mismo trato en el reconocimiento y ejecución que las sentencias 
dictadas por los tribunales. Aunque requiere de la cooperación jurídica y judicial entre los Estados, no requiere la designación de autoridades centrales.

Por últitno, la Convención Interamericana sobre Cumplimiento de Medidas Cautelares establece un marco parala aplicación extraterritorial de un proceso por medio del cumplimiento de medidas preventivas adoptadas en procedimientos de naturaleza comercial, laboral y civil, así como de las que se decreten para asegurar la reparación civil derivada de un procedimiento penal. Con respecto a esta Convención solo dos de los siete Estados parte han designado una autoridad central.

Para mayor información sobre estos instrumentos sobre derecho comercial y medidas preventivas, así como la designación de autoridades centrales, wéase el ANEXO VI del presente y la siguiente página web: www.oas.org/di/esp/dexecho_intemacional_privado_materas_comercialhtm

\section{E. Conclusiones:}

El sistema interamericano cuenta con un marco legal completo de convenciones sobre cooperación jurídica y judicial y asistencia legal mutua que abarca desde el derecho procesal hasta el derecho penal y el derecho de familia. Bajo las directrices de la REMJA, la OEA ha desarrollado esfuerzos para lograr una mayor cooperación en materia penal entre los Estados. Sin embargo, poco se ha hecho aún respecto de la implementación de instrumentos intezamericanos en materia de derecho civil, pese a que ésta fue una preocupación manifestada desde la Primera REMJA

La meta inicial es la creación de una red de autoridades centrales y funcionarios gubemamentales tal cono lo solicitan las convenciones mencionadas. Para lograr este objetivo, los Estados que aún no lo han hecho deberían designar autoridades centrales con relación a cada instrumento de los cuales sean parte. En algunos casos es posible que las autoridades centrales que actualmente desempeñan funciones bajo algunas convenciones de derecho público pudieran también efectuar estas funciones y cumplir con las obligaciones bajo otros tratados.

Otra meta importante es la creación de una guía de mejores prácticas para la operación de autoridades centrales y brindar capacitación a los funcionarios gubernamentales que desempeñan esas labores, así como facilitar el intercambio de información entre las autoridades centrales del sistema interamericano, con el apoyo de la Secretaría General de la OEA, a través de su Departamento de Asuntos Jurídicos Intemacionales, cuya Oficina de Derecho Internacional cumple además las funciones de depositaria de todas las convenciones interamericanas, incluidas las que son materia de esta propuesta.

Finalmente, sería necesario brindar a las autoridades centrales lass herramientas necesarias para desempeñar adecuadamente sus funciones y para comunicarse unas con otras de la manera más eficiente y segura. 


\section{ANEXo I}

Convención Interamericana de Derecho Internacional Privado (CIDIP) sobre la Ley Aplicable a Algunos Contratos y Relaciones de Consumo

\section{REGLAS GENERALES}

\section{Campo de Aplicación}

\section{Art. 1 - Definición de Consumidor}

1. A los efectos de esta Convención se entiende por Consumidor cualquier persona fisica que, frente a un profesional y en las transacciones, contratos y situaciones comprendidas por esta Convención, actúe con fines que no pertenezcan al ámbito de su actividad profesional.

2. Se consideran también consumidores a los terceros pertenecientes a la familia del consumidor principal u otros acompanantes, que usufructúan diretamente los servicios y productos contratados, en los contratos comprendidos por esta Convención, como destinatarios finales.

3. Para el caso de los contratos de viaje y de tiempo compartido, se considerarán consumidores:

a. el contratante principal o la persona física que compra o se compromete a contratar un viaje combinado o no, o un tiempo compartido para su uso próprio;

b. los beneficiarios o terceras personas en nombre de las cuales contrata o se compromete el contratante principal a contratar el viaje o paquete turístico y los que usufructuén del viaje o del tiempo compartido por algún espacio de tiempo, aunque no sean contratantes principales;

c. el cesionario o la persona física o jurídica a la cual el contratante principal o beneficiario cede el viaje o paquete turístico o los derechos de uso;

4. Si la ley indicada como aplicable por esta convención definiese de forma más amplia o benéficiosa quien debe ser considerado consumidor o equiparase a otros agentes como consumidores, o el juez competente puede tencr en cuenta esta extensión del campo de aplicación de la convención, si fuese más favoráble a los intereses del consumidor.

\section{Art. 2 - Protección contractual general}

1. Los contratos y las transaciones realizadas en las que participen consumidores, especialmente los contratos celebrados a distancia, por medios electrónicos, de telecomunicaciones o por teléfono, encontrándose el consumidor en el país de su domicilio, 
serán regidos por la ley de ese país o por la ley que fuera más favorable al consumidor, a elección de las partes, sea la ley del lugar de celebración del contrato, la ley del lugar de ejecusión, de la prestación más característica, o la ley del domicílio o sede del proveedor de los produtos o serviços.

2. Los contratos celebrados por el consumidor estando fuera del pás en el cual se domicilai se regirán por la ley que resulte elegida por las partes, quienes podrán optar por la ley del lugar de celebración del contrato, la ley del lugar de ejecusión o la del deomicilio del consumidor.

\section{Art. 3 Normas imperativas}

1. No obstante lo previs to en los articulos anteriores, se aplicarán necesariamente las normas del país del foro que tengan carácter imperativo, en protección del consumidor.

2. En el caso en que la contratación hubiera sido precedida por cualquier actividad negocial o de marketing, por parte del proveedor o de sus representantes, en especial el envio de publicidades, correspondencias, e-mails, premios, invitaciones, filiales existentes o representantes y demás actividades dirigidas a la comercialización de productos y servicios y la atracción de clientela en el país del domicilio del consumidor, se aplicarán necesariamente las nomas imperativas de ese país, para la proteción del consumidor, acumulativamente con aquellas del foro y de la ley aplicable al contrato o relación de consumo.

\section{Art. 4. Cláusula de excepción}

1. La ley indicada como aplicable por esta Convención puede no ser aplicable en casos excepcionales, sí, teniendo en vista todas las circunstancias del caso, la conexión con la ley indicada como aplicable resultara superfisial y el caso se encontrara más es trechamente vinculado con otra ley más favorable al consumidor.

\section{Art. 5 . Temas excluídos}

1. Quedan excluídos del campo de aplicación de esta convención:

a. los contratos de transporte regulados por Convenciones Intemacionales;

b. los contratos de seguros;

c. las obligaciones contratuales excluídas expresamente del campo de aplicación di CIDIP V sobre contratos internacionales .

d. los contratos comerciales intemacionales entre comerciantes o profesionales;

e. los demás contratos y relaciones de consumo, y las obligaciones de ellos resultantes, que incluyendo consumidores, se encuentren regulados por convenciones específicas; 


\section{PROTECIÓN EM SITUACIONES ESPECÍFICAS}

\section{Art. 6 - Contratos de viaje y turismo}

1. Los contratos de viajes individuales contratados en paquete o con serviços combinados, como grupo turístico o conjuntamente con otros servicios de hotelería y/o tuŕsticos, serán regulados por la ley del lugar del domicilio del consumidor, si este coincidiese con la sede o filial de la agencia de viajes con la que celebró el contrato de viaje o donde fue realizada la oferta, publicidad o cualquier acto negocial previo por parte del comerciante, transportador, agente o sus representantes autónomos.

2. En los demás casos, a los contratos de viajes individuales contratados en paquete o combinados, como grupo turístico o conjuntamente con otros servicios de hoteleria $\mathrm{y} / \mathrm{o}$ turísticos será aplicable ta ley del lugar en el cual el consumidor emite su aceptación contractual.

3. Los contratos de viajes no regulados por convenciones intemacionales, concluídos a través de contratos celebrados por adhesión o condiciones contractuales generales, será aplicable la ley del lugar donde el consumidor declara su aceptación contractual.

\section{Art. 7 - Contratos de tiempo compartido}

1. Las normas imperativas de protección de los consumidores del país en el cual se encuentren localizados fisicamente las instalaciones de esparcimiento y de hoteleria que utilicen como método de venta, de uso o de habitación el contrato de tiempo compartido, localizados en los Estados Partes, se aplicarán acumulativamente a estos contratos, a favor del consumidor.

2. Las normas del pais en que fuese realizada la oferta, la publicidad o cualquier actividad de marketing, tales como telefonemas, invitaciones a asistir a recepciones, reuniones, fiestas, envío de premios, realización de sorteos, estadias o ventas gratuitas, entre otras actividades negociales realizadas por los representantes o por los propietanios, organizadores o administradores de tiempos compartidos o la suscripción de pecontratos o contratos de tiempo compartido o derecho de uso por tumo de bienes inmuebles, debetán ser cnsideradas a favor del consumidor, cuanto la información, o derecho de arrepentimiento y sus plazos, asi como como las causas de rescisión del contrato o precontrato, así como determinarán el exacto contenido del contrato celebrado y la posibilidad o no de pago o de firma de cupones tarjetas de crédito en este periodo. 


\section{Anexo II}

\section{Propuesta de Estados Unidos para una Ley Modelo de la OEA sobre compensación monetaria aplicable a las transacciones de los consumidores}

- Los Estados Unidos apoyan la inclusión de un tema de protección al consumidor en la Séptima Conferencia Especializada Interamericana sobre Derecho Intemacional Privado (CIDIP.. VII). Los Estados Unidos creen que unas leyes e instituciones de protección al consumidor sólidas y eficaces contribuirían al bienestar del consumidor y al desarrollo económico de los páses de la OEA.

- Los Estados Unidos reconocen que existe una necesidad de elaborar mecanismos para proteger a los consumidores que han sufrido perjuicios económicos causados por empresas, en particular en los casos de perjuicios que tienen un valor monetario relativamente pequeño. Por consiguiente, los Estados Unidos proponen que la CIDIP se concentre en fomentar mecanismos de compensación monetaria al consumidor.

- Específicamente, los Estados Unidos proponen que la CIDIP se dedique a elaborar una ley modelo sobre mecanismos para que los consumidores obtengan compensación monetaria. Hay muchas vías posibles para la compensación, entre ellos los mecanismos judiciales como los tribunales para demandas de menor cuantía y la adjudicación administrativa de las mismas, o las demandas colectivas privadas, de asociaciones y gubernamentales (en representación de intereses comunitarios). Una ley modelo abarcaría algunas de estas opciones o todas ellas.

- Por ejemplo, una ley modelo podría presentar una declaración básica sobre el derecho a la compensación monetaria y la disponibilidad de mecanismos para la reparación en casos de quejas de los consumidores. Esa declaración podría expresarse en los siguientes términos generales: La compensación monetaria a los consumidores por perjuicios económicos podrá obtenerse por medio de mecanismos administrativos o judiciales para adjudicaciones particulares de demandas de menor cuantía y por medio de pleitos colectivos o representativos presentados ante tribunales generales o administrativos $u$ otros juzgados pertinentes.

- Con respecto a los procedimientos de las demandas de menor cuantía, una ley modelo sentaría algunos principios básicos para un procedimiento que sea de bajo costo, eficiente y ágil. No requetría que los paises miembros establecieran tribunales especificamente para estos procedimientos sino que dejarian la selección del mecanismo exacto al criterio de cada país 'por ejemplo, un tribunal especializado, un tribunal administrativo o una entidad nacional de protección al consumidor). 
- En lo relativo a los pleitos colectivos o de representación, la ley modelo especificaría las entidades que estarian facultadas para presentar demandas colectivas o de representación en procura de compensación monetaria, que podrian consistir en entidades públicas o abogados que representen a una clase de consumidores que tengan reclamaciones comunes. La ley modelo especificaría que los procedimientos de acción colectiva son adecuados para obtener compensación monetaria para consumidores particulares.

- La ley modelo también podría contener una disposición que aclare que las sentencias relativas a compensación monetaria en pleitos colectivos interpuestos por gobiemos no se consideren de indole penal o pública y que deberían hacerse cumplir según las notmas del derecho internacional privado. El Acuerdo de Libre Comercio entre los Estados Unidos y Australia tiene una disposición similar.

- El tema de los mecanismos de compensación ya ha atraído la atención de los estados miembros de la OFA y del Foro de entidades latinoamericanas de protección al consumidor. En realidad, muchas entidades latinoamericanas y sudamericanas de protección al consumidor han comenzado a explorar los mecanismos mediante los cuales los consumidores pudieran obtener compensación monetaria. Algunos países, como México, han instituido procedimientos para las reclamaciones de menor cuantía de carácter administrativo. Otros países están estudiando los mecanismos de acción colectiva. Por ejemplo, recientemente Chile aprobó una ley que confiere al gobiemo la capacidad de interponer demandas colectivas en nombre de los consumidores. F1 Brasil, que ha sido pionero en Sudamérica en materia de acciones colectrvas, en la actualidad está realizando estudios de factibilidad sobre la ampliación de su procedimiento para estas demandas. La entidad de protección al consumidor de México, PROFECO, ya tiene la facultad de interponer acciones colectivas en nombre de los consumidores.

- En los últimos tiempos este tema ha atrádo mucha atención también en otros páses. Actualmente, los 30 Estados Miembros de la OCDE estudian los mecanismos de compensación al consumidor. El Comité de Políticas del Consumidor de este organismo celebrará un taller sobre este tema en Washington, D. C. en abril de 2005, en el cual participará México. La reunión de la OCDE pudiera proporcionar antecedentes útiles para la reunión de la CIDIP.

- Una ley modelo sobre compensación al consumidor complementaría la propuesta de una convención sobre las normas de selección del derecho aplicable al consumidor, puesto que se concentraría en los mecanismos prácticos de compensación.

- Si se incluyen temas orientados al consumidor se lograńa un programa de temas equilibrado, en el que fuguranía también un tema de índole económica, como el que proponen los Estados Unidos y cuenta con el apoyo de varios miembros de la OEA, dirigidos a realzar el desarrollo económico y el comercio en todas las Américas. 


\section{ANEXO III}

\section{Propuesta del Canadá sobre una Ley Modelo sobre Jurisdicción y Normas Legales Aplicables Uniformes en Materia de Contratos con el Consumidor}

En el contexto de CIDIP-VII, Canadá propone la elaboración de un instrumento sobre contratos con el consumidor que se refiera a los fundamentos por los cuales un tribunal entendería en un caso en que participaran partes extraestatales y qué leyes del Estado se aplicarian a la resolución del caso.

La finalidad de ese instrumento consistiria en establecer normas de jurisdicción uniformes con tespecto a los contratos trans fronterizos entre empresas y consumidores. Aunque siempre han existido cuestiones de jurisdicción, el aumento del número de transacciones transfronterizas que tienen lugar a través de la Intemet les ha conferido más importancia. Al aumentar las transacciones transfronterizas es importante que el marco jurídico que respalda las transacciones con el consumidor más allá de las fronteras de los Estados se rija por principios frrmes, que den lugar a resultados previsibles, sea cual fuere el Estado en que esté ubicado determinado consumidor o vendedor.

Una de las consecuencias inevitables de que diariamente se celebren numerosos contratos con el consumidor en que éste y el vendedor estén situados en diferentes Estados es que algunas de esas transacciones den lugar a controversias que sea preciso resolver. En todos los casos en que la controversia traspasa fronteras nacionales se plantean preguntas acerca de qué tribunal es competente para entender en la controversia (clección del tribunal competente) y la legislación de qué Estado debe aplicarse para resolver la controversia (legislación aplicable). Esos dos temas son claramente dife rentes, pero plantean muchas consideraciones iguales, colcctivamente denominadas normas sobre conflictos de leyes.

Aunque las transacciones con el consumidor, realizadas electrónicamente o por otros medios, están sujetas a normas tradicionales relativas a competencia, el comercio electrónico plantea dificultades para la aplicación de ese marco existente. I a inexistencia de fronteras que caracteriza a la Internet hace dificil determinar el lugar de celebración de un contrato. Los tribunales han utilizado diversos criterios para establecer si son competentes y la legislación de qué Estado debe regir la resolución de controversias sobre transacciones realizadas a través de la Intemet.

En cuanto unifica las normas sobre conflictos de leyes aplicables en los Estados en materia de controversias sobre contratos con el consumidor, el instrumento propuesto garantizaría la aplicación de idéntica solución sea cual fuere el tribunal que entendiera en el caso. El régimen legal está destinado a brindar mayor certidumbre y previsibilidad a los resultados para la resolución de controversias referentes a contratos transfronterizos con el 
consumidor. El instrumento se aplicaría en los casos en que la controversia abarcara a más de un Estado y no se limitaría a controversias surgidas de transacciones realizadas a través de la Internet, sino a todas las controversias emanadas de contratos con el consumidor, se realicen o no en línea.

Al elaborar un instrumento de ese género deberian considerarse los siguientes objetivos de políticas:

- La protección del consumidor en línea no debe ser menos eficaz que la que rige para las transacciones con el consumidor realizadas a través de medios de comunicación tradicionales.

- Los consumidores deben gozar de los beneficios de la protección que nomalmente les ofrecen las leyes de protección del consumidor vigentes en el lugar en que viven.

- La ley debe ser tecnológicamente neutra, en el sentido de que no debe establecer discriminaciones entre diferentes formas de tecnología.

- Debe existir certeza con respecto a las nomas aplicables a los participantes y a sus transacciones, para que aquellos puedan prever su situación furídica antes de celebrar: transacciones comerciales.

- El riesgo jurídico de operar en línea no debe ser desproporcionado con la conexión de un vendedor con la legislación y los tribunales del foro pertinente.

- Los vendedores deben poder optar por operar o no dentro del marco jurídico de determinado Estado.

- Las nomas sobre conflictos de leyes no deben ser un impedimento al continuo crecimiento del comercio electrónico. 


\section{ANEXo IV}

\section{FORMULARIO INTERAMERICANO UNIFORME DE INSCRIPCION REGISTRAL}

\section{(Formulario - 1)}

(Ley Modelo interamericana Sobre Garantias Mobiliarias)

1. DEUDOR GARANTE (NOMBRE COMPLETO) - soio wn nombre

PERSONA JURIDICAMORALi NOmbre
Num. de tgentlficación

2. DEUDOR GARANTE ADICIONAL (NOMBRE COMPLETO) - solo Ur nombre

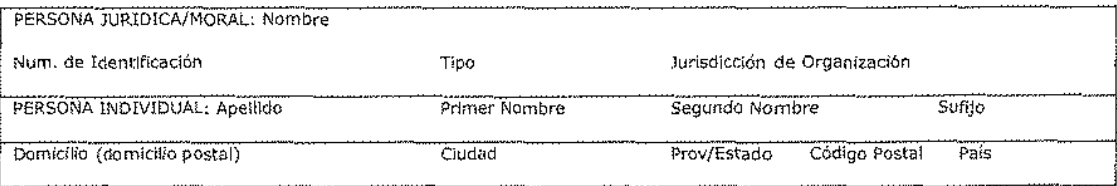

\section{ACFEEDOR GARANTIZADO}

PERSONA JURIDICA MORAL; Nomore
Num. de Identificación
PERSONA INDIVIDUAL: Apeiltdo

\section{MONTO MAXIMO GARANTYZADO POR LA GARANTTA MOBILYARIA}

\section{OESCRYPCION DE LOS BIENES EN GARANTKA}

5a. DESCRIPCION GENERAL DE LOS B!ENES:

5b. Bienes de Nímero de Serie (sl aplica, opcionat)

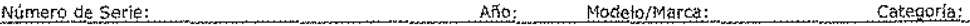

5c. Inscripeidn Cubre: $\square$ Crectitos $\square$ obligactones No Monetarias $\square$ Cartas de Credito $\square$ propiedad Intelectual $\square$ Inventario $\square$ Garantia Flotante $\square$ eienes Adherlalos $\square$ instrumentos/Documentos $\square$ Insts/Docs Electrónicos

5d. Bjenes Muebies Atribulbles: $\square$ Descripción General de los Bienes en Garantia

5e. Garantia Mobiliaria de Adqutsiclón $\square$ Por favor complete el anexo 1 si ha martado esta castla

6. Contratos Registrabies: $\square$ LEASING $\square$ CONSIGNACION[] ALMACEN $\square$ VENTA CONDICIONAL $\square$ FIDECOMISO

7. Duración: Là duración seráa de cinco ahos a partir de la fectia de inscripción, sajvo indicación en contrario a continuazción
A.NัOS MESES
DIAS
(O) FECHA DE VENCEMIENTO; DIA MES ANัO

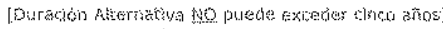

\section{PARTE REGISTRANTE}

\begin{tabular}{|c|c|c|c|}
\hline PERSONA INDEVIDUAL; ApEilido & Primer Nombre & Segundo Nombre & SUIfjo \\
\hline Domicilio (ctomicilio postal) & Ciudad & Código Postai & País \\
\hline Firma & & Numero de Teléfono & \\
\hline
\end{tabular}

[ADVERTENCIA: Completer de maneră cuidadosa. Errores pueden causar importantes consecuencias jurídicas] 


\section{INSTRUCCIONES FORMULARIO INTERAMERICANO UNIFORME DE INSCRIPCION REGISTRAL}

\section{Item I - Nombre def Deudar Garante:}

Complete solo un nombre en ftem 1. Complete ton el nombre dei Deurdor

Parsona_Juridica: significa una entidad que tenga personaría legat separada de sus propietarios una sociedad as una persona juridica; un solo propletario no es una sociedad, incluso si realiza actlvidad comercial bajo un nombre comerctat. St el deudor es und sociedad, completar con el nombre legal completo de la sociedad; No necesita ingresar los nombres de los miembros tomo deudores adkionales. Si el deudor es una persona Juridlca (e.g. Sociedad Anónima sociedad de Responsabilidad Limitade), Es aconsejable examinar el estatuto de 12 societad (contrato soclal;) para determinar el Nombre cortecto de la Sociedad Deudora; Tipo de Sociedad y Jusisdicción de Creación.

Persona Individual: es ia persona de existencia real; incluye al propietario, sin importar cue opere bajo nombre comercial.

Romlciltio: el domiclio es siempre requerido para el deutor designado.

Numero de Identificactón: Numero de Seguridad Social o Numero de Identificación personal o Numero de la Sociedéd.

Tipo de Sociedad: (e.g, Sociedad Anónime, Sociedad de Responsabilidad tirritada, Corporación, etc.)

Jurisdicclón de Creación: es el tugar donde fue registrada por primero vez la Sociedad.

\section{Item 2 - Deudor Adictonal:}

Si un deudor adłcional es intulato, complete ítem 2 , según las histrucción del item 1..Para incluir un Deudor adicional, o un Acreedor Garantizado adicional, adfuntar un Anexo o pagina adtcional siguiendo el formato del f́tem 1.

\section{Item 3 - Acreedor Garantizado:}

Completar la Información dé Acreedor Garantizado según lo determinado y siguierdo el formato del ítem 1

\section{Item 4 - obligación Garantizada:}

Completar el monto máxime de la deuda garantizada con la inscripción de lü garastía mobiliaria.

\section{Item 5 - Bien Mueble en Garantia:}

ftern 5(a): Utillce el item 5 para indicar el o los bienes que cubre esta lnscripción. Si el espacto es insuficiente complete la descripción de los bienes en garantia en un formulario anexo o en una(s) pagins(s) adicional(es)

f́cm 5(b): Indique los mumeros de serie de los blenes muebles inscriptos (si aplica). El uso de este campo es opclonal.

Itern $5(c)$ : Marque la casilla apropiada si ta garantia mobiliaria cubre créditos, obligaciones no monetarias, cartas de crédito, instrumentos o documentas, inventartos derechos de propiedad intelectual, bienes adheridos, Garantia flotante, instrumentos o doctumentos edectróntcos.

\section{Item 5 - Bien Mueble en Garantía (Continuación)}

Ítem 5 (d): Controlar si la garantía mobiliaria inchuye gienes Muebles Atribuible y agregar una descripclón general del mlsmo [Blenes Muebles Atribulbles es una garantía mobiliaria que puede identificarse como derivada del bien mueble origlinal, como frutos - productos, o el producto resultante de su venta, sisstitutión o transformación.]

Item 5(e): 5 i ha marcado la castla de Garantla Mobiliaria de Adouisicion, tomplete el Anexo 1. [Garantia Mobistaria de Adquisición es una garantía en favor del acreedor -vendedorquien financia la adquisición del bien muebie del deudor sobre el cual recae la garantia. Con esta Garantía mobttiaria de Adquisición se puede financior la adquisición de bienes presentes o subsigulertes.]

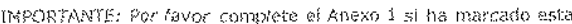
Casijist

\section{Item 6 - Otros Contratos Registrables:}

Marcar la casil|a correspondlente según la inscripción corresponde a un contrato de Leasing, Consignación, Almactén, venta Condicional o Fidecomiso.

\section{Item 7 - Duración:}

Complete con la duraclón de la inscripción de la garantía mobiliaria, o con la fecha de vencimiento, que no puede exceder de cinco años, renovatles por un témino de tres afros preservando la prioridad origlnal. No obstante las partes pueden establectes una duración diferente dentro de ese periodo de tiernpo.

\section{Item B - Parte Registrante:}

Información de la parte que reaikz la inscripción.

Notas:

- La garantía Mobiliaria adquiere pubicldad con $\$$ is inscripclón $\gamma$ adquiere efectos frente a terceros desde el momento de su inscripción

- El Derecho conferido por la garantía moblliarla con respecto a los bienes en garantía es oponible a terceros soto cuando el requistio de publicidad ha sido completado.

- La prioridad oe la garantia esta estabiecida al tiempo de su pubticidad. $l a$ garantía mobitiarla confiere al acreedor garantizado ef derectio de perseguls los blenes en garantia para ajercer sus derechos carantizados

- La publicldad de la Garantía Mobiliaria sobre un bier miseble que es adherido a un innueble, sin perder su identldad de blen mueble, tiene prioridad sobre las Garantias que afecten: el inmereble, siernpre que ta Garantia Moblliaria sobre los bienes muebles halla sido registrada en el registro antes de ser adherido. 


\section{ANEXO V}

Convenciones en Materia de Derecho Procesal: Estado de Ratificactones y Designación de Autoridades Centrates

\begin{tabular}{|c|c|c|c|c|c|}
\hline & 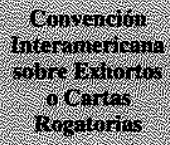 & 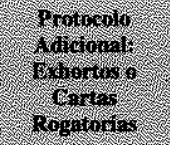 & 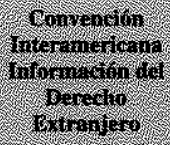 & 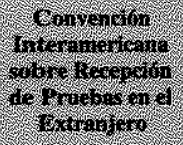 & 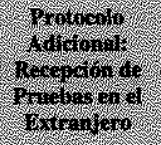 \\
\hline $\begin{array}{l}\text { Antigua y } \\
\text { Barbuds }\end{array}$ & $\sim$ & $\cdots$ & $\cdots$ & -- & $m$ \\
\hline Argentins & No Desłg̣ó A.C. & No Designó A.C. & No Designó A.C. & No Designo A.C. & No Designó $\mathrm{A}, \mathrm{C}$. \\
\hline Baliamas & -- & -- & - & $\cdots$ & -- \\
\hline Barbados & $\cdots$ & 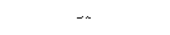 & $\sim w$ & $\cdots$ & $\cdots$ \\
\hline Belice & $\cdots$ & $\because$ & -- & -- & -- \\
\hline Bolivia & $\begin{array}{l}\text { Firmó peto no } \\
\text { Ratificó }\end{array}$ & $\begin{array}{l}\text { Firmó peto no } \\
\text { Ratificó }\end{array}$ & $\begin{array}{l}\text { Firmó pero no } \\
\text { Ratíficó }\end{array}$ & $\begin{array}{c}\text { Firmó pero no } \\
\text { Ratificó }\end{array}$ & $\begin{array}{l}\text { Firmó pero no } \\
\text { Ratífico }\end{array}$ \\
\hline Brasil & $\begin{array}{l}\text { Minlsterio de } \\
\text { Justicla }\end{array}$ & No Designó A.C. & No Designó A.C. & $\begin{array}{l}\text { Firmó pero no } \\
\text { Ratificé }\end{array}$ & $\begin{array}{l}\text { Fimmó pero no } \\
\text { Ratificó }\end{array}$ \\
\hline Canada & $-\cdots$ & $\ldots$ & $\cdots$ & -- & nn \\
\hline Chile & $\begin{array}{l}\text { Ministerio de } \\
\text { Redaciones } \\
\text { Exteriores }\end{array}$ & No Designó A,C. & No Desłgnó A.C. & $\begin{array}{l}\text { Dirección de } \\
\text { Asuntos jurfdicos } \\
\text { del Ministerlo de } \\
\text { Refaciones } \\
\text { Exteriores }\end{array}$ & $\begin{array}{l}\text { Firmó pero no } \\
\text { Ratiffé }\end{array}$ \\
\hline Colombia & No Designó A.C. & No Designó A.C. & $\begin{array}{l}\text { Ministerio de } \\
\text { Relaciones } \\
\text { Exteriores }\end{array}$ & No Designó A.C. & $\begin{array}{l}\text { Firmó pero no } \\
\text { Ratiflcó }\end{array}$ \\
\hline Costa Rica & No Designó A.C. & $\begin{array}{l}\text { Firró pero no } \\
\text { Ratificó }\end{array}$ & $\begin{array}{l}\text { Firmó pero no } \\
\text { Ratificó }\end{array}$ & No Designó A.C. & 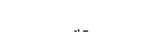 \\
\hline Dominica & $\cdots$ & $\ldots$ & -- & - & $\cdots$ \\
\hline Ecuador & $\begin{array}{c}\text { Asesoría } \\
\text { Técnico-Juridica } \\
\text { del Ministerio de } \\
\text { Relaciones } \\
\text { Exteriores }\end{array}$ & $\begin{array}{l}\text { Asesoria } \\
\text { Técnlco-jurídica } \\
\text { del Ministerto de } \\
\text { Relaciones } \\
\text { Exterlores }\end{array}$ & No Designó A.C. & $\begin{array}{c}\text { Ministerio de } \\
\text { Relaciones } \\
\text { Exteriores - } \\
\text { Asesoria } \\
\text { Técnlcom-juridlca- } \\
\text { Dirección } \\
\text { General de } \\
\text { Asuntos Legales }\end{array}$ & No Designó A.C. \\
\hline España & $\begin{array}{c}\text { Secretaría } \\
\text { General Técnica } \\
\text { del Ministertio de } \\
\text { Justitia }\end{array}$ & $\cdots$ & $\begin{array}{c}\text { Secretaría } \\
\text { General Técnica } \\
\text { del Ministerio de } \\
\text { Justicia }\end{array}$ & $\cdots$ & $\cdots$ \\
\hline Ed Salvador & $\begin{array}{c}\text { Corte Suprema } \\
\text { de Justicia }\end{array}$ & $\begin{array}{c}\text { Corte Suprema } \\
\text { de Justicia }\end{array}$ & $\begin{array}{l}\text { Firmó pero no } \\
\text { Ratificó }\end{array}$ & $\begin{array}{l}\text { Corte Suprema } \\
\text { de Justtcia }\end{array}$ & $\cdots$ \\
\hline $\begin{array}{l}\text { Estados } \\
\text { Unidos }\end{array}$ & $\begin{array}{l}\text { Department of } \\
\text { justice: Office of } \\
\text { Int'l. Legal } \\
\text { Assistance, CivH } \\
\text { Division }\end{array}$ & $\begin{array}{l}\text { Department of } \\
\text { Justice: Office of } \\
\text { Int?! Legal } \\
\text { Assistance, Civlt } \\
\text { Division }\end{array}$ & $\sim$ & n- & $\cdots$ \\
\hline
\end{tabular}




\begin{tabular}{|c|c|c|c|c|c|}
\hline & 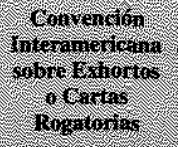 & 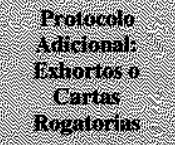 & 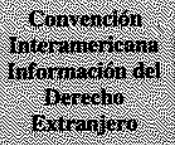 & 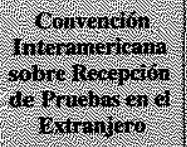 & 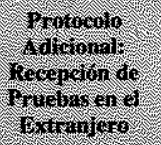 \\
\hline Grenada & - & $\sim$ & $\cdots$ & $\cdots$ & $m$ \\
\hline Guatemala & $\begin{array}{l}\text { Corte Suprema } \\
\text { de Justicia }\end{array}$ & No Designó A.C. & $\begin{array}{l}\text { Corte Suprema } \\
\text { de Justicia }\end{array}$ & $\begin{array}{l}\text { Corte Suprema } \\
\text { de Justicia }\end{array}$ & $\cdots$ \\
\hline Gtiyana & $\sim$ & -- & $\cdots$ & $-\infty$ & $\cdots$ \\
\hline Haiti & $\cdots$ & $\begin{array}{l}\text { Firmó pero no } \\
\text { Ratificó }\end{array}$ & $\begin{array}{l}\text { Flrmó pero no } \\
\text { Ratificó }\end{array}$ & $\sim$ & -- \\
\hline Honduras & No Designd A.C. & $\begin{array}{l}\text { Firmó pero no } \\
\text { Ratficó }\end{array}$ & $\begin{array}{l}\text { Fitmó pero no } \\
\text { Ratificó }\end{array}$ & No Designó A,C. & $\cdots$ \\
\hline Jambica & -- & $\cdots$ & .. & ... & $n$ \\
\hline México & $\begin{array}{l}\text { Secretaría de } \\
\text { Relaciones } \\
\text { Exteriores }\end{array}$ & $\begin{array}{l}\text { Secretaria de } \\
\text { Relaciones } \\
\text { Exteriores }\end{array}$ & $\begin{array}{l}\text { Secretaria de } \\
\text { Relaciones } \\
\text { Exteriores }\end{array}$ & $\begin{array}{l}\text { Secretaria de } \\
\text { Relaciones } \\
\text { Exteriores }\end{array}$ & $\begin{array}{l}\text { Secretaría de } \\
\text { Relaciones } \\
\text { Exteriores }\end{array}$ \\
\hline Nicaragua & $\begin{array}{l}\text { Firmó pero no } \\
\text { Ratificó }\end{array}$ & 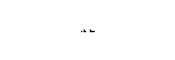 & -- & $\begin{array}{l}\text { Firmó pero no } \\
\text { Ratificó }\end{array}$ & $\begin{array}{l}\text { Firmó pero no } \\
\text { Ratíficó }\end{array}$ \\
\hline Panamá & No Designń A.C. & $\begin{array}{l}\text { Ministerio de } \\
\text { Relaciones } \\
\text { Exteriores }\end{array}$ & $\begin{array}{c}\text { Firmó pero no } \\
\text { Ratiffeo }\end{array}$ & $\begin{array}{l}\text { Minfsterio de } \\
\text { Relaclones } \\
\text { Exteriores }\end{array}$ & -- \\
\hline Paragxay & No Designó A.C. & No Designó A.C. & No Designó A.C. & No Designó A.C. & $\begin{array}{l}\text { Firmó pero no } \\
\text { Ratificó }\end{array}$ \\
\hline Perú & No Designó A.C. & No Designó A.C. & $\begin{array}{l}\text { Corte Suprema } \\
\text { de Justicia }\end{array}$ & No Designó A.C. & $\begin{array}{l}\text { Firmá pera no } \\
\text { Ratíficó }\end{array}$ \\
\hline $\begin{array}{c}\text { República } \\
\text { Dominicama }\end{array}$ & $\cdots$ & $\begin{array}{l}\text { Firmó pero no } \\
\text { Ratificó }\end{array}$ & $\begin{array}{l}\text { Finmó pero no } \\
\text { Ratificó }\end{array}$ & No Designó A.C. & $\begin{array}{l}\text { Firmó pero no } \\
\text { Ratifico }\end{array}$ \\
\hline $\begin{array}{l}\text { Snn Kitls y } \\
\text { Nevis }\end{array}$ & $\cdots$ & $\ldots$ & -- & -- & $\sim$ \\
\hline San Lucía & - & $\cdots$ & $\cdots$ & $\cdots$ & $\cdots$ \\
\hline $\begin{array}{c}\text { St. Vimcent } \\
\& \\
\text { Grenadines }\end{array}$ & $\cdots$ & $\ldots$ & $\cdots$ & $\cdots$ & $r$ \\
\hline Suriname & $\sim$ & $\cdots \cdot$ & $\cdots$ & $\cdots$ & $\cdots$ \\
\hline $\begin{array}{c}\text { Trinidad \& } \\
\text { Tobago }\end{array}$ & - & $\cdots$ & $-\infty$ & $\cdots$ & $-\%$ \\
\hline Uruguay & $\begin{array}{l}\text { Ministerio de } \\
\text { Educación y } \\
\text { Cuktura: Asesoria } \\
\text { Autoridad } \\
\text { Central Coop. } \\
\text { Juridica } \\
\text { Internacional }\end{array}$ & $\begin{array}{l}\text { Ministerto de } \\
\text { Educación y } \\
\text { Cultura: Asesoría } \\
\text { Autoridad } \\
\text { Central Caop. } \\
\text { Jurídtca } \\
\text { International }\end{array}$ & $\begin{array}{c}\text { Ministerio de } \\
\text { Educación y } \\
\text { Cultura: Asesoría } \\
\text { Autoridad } \\
\text { Central Coop. } \\
\text { Jurídica } \\
\text { Internacional }\end{array}$ & $\begin{array}{l}\text { Ministerio de } \\
\text { Educación y } \\
\text { Cultura: Asesoria } \\
\text { Autoridad } \\
\text { Central Coop. } \\
\text { Jurldica } \\
\text { Internacional }\end{array}$ & $\begin{array}{l}\text { Firmó pero no } \\
\text { Rátifícó }\end{array}$ \\
\hline Venezuela & $\begin{array}{l}\text { Ministerto de } \\
\text { Relaciones } \\
\text { Exteriores }\end{array}$ & No Designó A.C. & No Designó A.C. & No Designó A.C. & No Designó A.C. \\
\hline
\end{tabular}




\section{ANEXo VI}

Convenciones en Materia de Derecho Faniliar y Protectión de Menores: Estacio de Ratilicaciones y Designación de Autoridades Centrales

\begin{tabular}{|c|c|c|c|}
\hline & 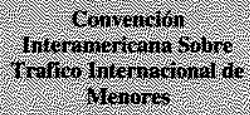 & 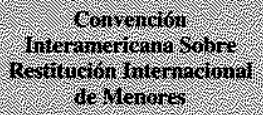 & 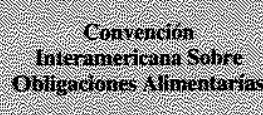 \\
\hline $\begin{array}{l}\text { Antigua y } \\
\text { Barbuda }\end{array}$ & $\cdots$ & $\begin{array}{c}\text { offlce of the Attorney } \\
\text { Genefal }\end{array}$ & $\cdots$ \\
\hline Argentina & No Dessignó A.C. & $\begin{array}{l}\text { Ministerlo de Relaciones } \\
\text { Exteriores, Comercio } \\
\text { Intemacional y Cutto }\end{array}$ & $\begin{array}{l}\text { Mwinisterio de Relaciones } \\
\text { Exteriores, Comercio } \\
\text { Intemacional y Cutto }\end{array}$ \\
\hline Bahamas & $\ldots$ & $\ldots$ & $\ldots$ \\
\hline Baryados & $-\cdot$ & $\ldots$ & $\cdots$ \\
\hline Belice & No Designó A.C, & No Designnó A.C. & No Designó A.C. \\
\hline Bolivia & $\begin{array}{l}\text { Dra. Elizabeth Patińo } \\
\text { Duran, Vicemfnistro de la } \\
\text { Juventud y Niñez }\end{array}$ & $\begin{array}{l}\text { Dra. Elizabeth Patiño } \\
\text { Duran, Viceministro de la } \\
\text { Juventud y Niñez }\end{array}$ & No Designó A.C. \\
\hline Brasil & No Designó A.C. & No Designó A.C. & No Designó A.C. \\
\hline Canada & $\ldots$ & - & $\ldots$ \\
\hline Chife & -. & $-\infty$ & $\ldots$ \\
\hline Colombia & $\begin{array}{l}\text { Instituto Colombiano de } \\
\text { Bienestar Familia, } \\
\text { Intervenciones } \\
\text { Especializadas }\end{array}$ & Firmó pero no Rạtificó & Firmó pero no Ratifleó \\
\hline Costa Rica & No Designó A.C. & No Designó A.C. & No Dessignó A.C. \\
\hline Dombinica & -- & -- & $\cdots$ \\
\hline Eeuador & $\begin{array}{l}\text { Or. Iván Gomezjurado } \\
\text { Cevallos, Presidente, } \\
\text { Consejo Nacional de la } \\
\text { Niñez y la Adolescencia }\end{array}$ & $\begin{array}{l}\text { Dr. Iván Gomezjurado } \\
\text { Cevallos, Presidente, } \\
\text { Consejo Nacional de la } \\
\text { Niñez y la Adolescencia }\end{array}$ & $\begin{array}{l}\text { Dr. Iván Gomezjurado } \\
\text { Cevallos, Presidente, } \\
\text { Consejo Nacional de la } \\
\text { Niniez y la Adolescencia }\end{array}$ \\
\hline España & - & $\cdots$ & -- \\
\hline El Salvador & -- & $-\cdots$ & $\ldots$ \\
\hline $\begin{array}{l}\text { Estados } \\
\text { Unidos }\end{array}$ & $\cdots$ & $\ldots$ & -- \\
\hline Grenada & $\ldots$ & $\cdots$ & $\ldots$ \\
\hline Giatemsila & $\ldots$ & Firmó pero no Ratifleó & No Dessignó A.C. \\
\hline Guyana & -- & $\cdots$ & -- \\
\hline Haiti & r & Firmó pero no Ratificó & Firmó perc no Ratificó \\
\hline Honduras & -- & -- & -- \\
\hline Jamaica & $\ldots$ &.- & $\ldots$ \\
\hline México & Firmó pero no Ratificó & $\begin{array}{l}\text { Secretaria de Relaciones } \\
\text { Exteriores, Oficina de } \\
\text { Derecho de Familia }\end{array}$ & No Destgnó A.C. \\
\hline
\end{tabular}




\begin{tabular}{|c|c|c|c|}
\hline & 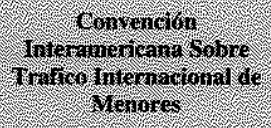 & 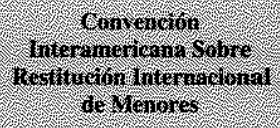 & 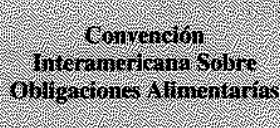 \\
\hline Nicaragua & $-\infty$ & $\begin{array}{c}\text { Concejo Nacional de } \\
\text { Atención y Protección } \\
\text { Integrat a la Niñez y la } \\
\text { Adolescencia (CONAṔNA) }\end{array}$ & .. \\
\hline Panamá & No Designó A.C. & $\therefore$ & No Designó A.C. \\
\hline Paraguay & No Designó A.C. & $\begin{array}{c}\text { Secretaría Nacional de la } \\
\text { Niffez y la Adolescencia }\end{array}$ & No Designó A.C. \\
\hline Perú & No Designó A.C. & No Designó A.C. & Firmó pero no Ratificó \\
\hline $\begin{array}{l}\text { República } \\
\text { Dominicana }\end{array}$ & $\cdots$ & -- & * \\
\hline $\begin{array}{c}\text { San Kitts y } \\
\text { Nevis }\end{array}$ &.- & - & $\ldots$ \\
\hline San Lucía & - & $\cdots$ & - \\
\hline $\begin{array}{c}\text { St. Vincent \& } \\
\text { Greuarlines }\end{array}$ & $\cdots$ & $\ldots$ & $\ldots$ \\
\hline Suriname & $\cdots$ & $\cdots$ & -- \\
\hline $\begin{array}{c}\text { Trinidad \& } \\
\text { Tobago }\end{array}$ & $\cdots$ & $\cdots$ & w \\
\hline Uruguay & No Designó A.C. & No Designó A.C. & No Designó A.C. \\
\hline Venezuela & Firmó pero no Ratificó & $\begin{array}{c}\text { Ministerio de Relaciones } \\
\text { Exteriores }\end{array}$ & Firmó pero no Ratlfficó \\
\hline
\end{tabular}




\section{ANEXo VII}

Otras Convenciones en Matería de Derecho Comercial y Medidas Cautelares: Fstado de Ratificaciones y Designación de Autoridades Centrales

\begin{tabular}{|c|c|c|}
\hline & 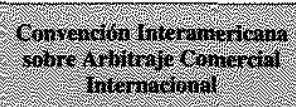 & 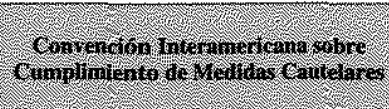 \\
\hline Antigua y Barbuda & $\ldots$ & $\cdots$ \\
\hline Argentina & No Requiere A.C. & $\begin{array}{c}\text { Ministerio de Relaciones Exteriores y } \\
\text { Culto }\end{array}$ \\
\hline Bahamas & $\cdots$ & - \\
\hline Barbados & -- & $\cdots$ \\
\hline Bellue & $-\cdots$ & -- \\
\hline Bolivia & No Requiere A.C. & Firmó pero no Ratificó \\
\hline Brasil & No Requiere A.C. & $\cdots$ \\
\hline Canada & $\cdots$ & -- \\
\hline Chile & No Requiere A.C. & Firmó pero no Ratificó \\
\hline Colombia & No Requiere A.C. & No Designó A.C. \\
\hline Costa Rica & No Requiere A.C. & Fimmó pero no ha Ratificó \\
\hline Doninica & $\cdots$ & -- \\
\hline Ecuador & No Requiere A.C. & No Designó A.C. \\
\hline España & $\cdots$ & - \\
\hline El Salvador & No Requiere A.C. & No Designó A.C. \\
\hline Estados Unidos & No Requiere A.C. & 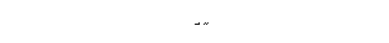 \\
\hline Grenada & $\cdots$ & $\cdots$ \\
\hline Guatemalg & No Requiere A.C. & -- \\
\hline Guyana & $-\infty$ & $\cdots$ \\
\hline Haiti & $\therefore$ & -- \\
\hline Honduras & No Requiere A.C. & No Designó A.C. \\
\hline Jamaica & - & . \\
\hline México & No Requlere A.C. & No Designó A.C. \\
\hline Nicaragua & No Requtere A.C. & No Designó A.C. \\
\hline Panamá & No Requiere A.C. & No Designó A.C. \\
\hline Paraguay & No Requiere A.C. & No Designò A.C. \\
\hline
\end{tabular}




\begin{tabular}{|c|c|c|}
\hline & 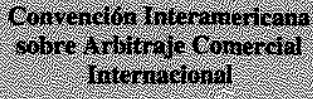 & 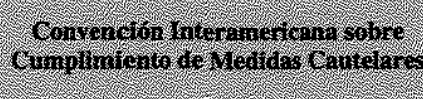 \\
\hline Perú & No Requiere A.C. & No Designó A.C. \\
\hline $\begin{array}{l}\text { Repứblica } \\
\text { Dominicana }\end{array}$ & Firmó pero no Ratificó & Firmó pero no Ratificó \\
\hline Sam Kitts y Nevis & $\cdots$ & $\sim$ \\
\hline San Lucía & $\cdots$ & $\cdots$ \\
\hline $\begin{array}{l}\text { St. Vincent \& } \\
\text { Grenadines }\end{array}$ & $\cdots$ & $\cdots$ \\
\hline Suriname & $\cdots$ & $m$ \\
\hline Trinidad \& Tobago & $\cdots$ & $\cdots$ \\
\hline Urugusy & No Requiere A.C. & $\begin{array}{l}\text { Ministerio de Educación y Cultura: } \\
\text { Asesoria Autoridad Central de } \\
\text { Cooperación Wurídica Internacional }\end{array}$ \\
\hline Venezuela & No Requiere A.C. & Firmó pero no Ratificó \\
\hline
\end{tabular}

